American Journal of Applied Sciences 7 (3): 376-380, 2010

ISSN 1546-9239

(C) 2010Science Publications

\title{
Geographic Information System-Allocation Model for Forest Path: A Case Study in Ayer Hitam Forest Reserve, Malaysia
}

\author{
I. Mohd Hasmadi, H.Z. Pakhriazad and F.S. Mohamad \\ Forest Surveying and Engineering Laboratory, Department of Forest Production, \\ Faculty of Forestry, University Putra Malaysia, 43400 UPM, Serdang, Selangor, Malaysia
}

\begin{abstract}
Problem statement: Forest road planning requires a host of information, particularly the availability of spatial and non-spatial data. The requirement of a planning system or tools to gather, integrate and manipulate all data is essential. The ability of Geographic Information System (GIS) to integrate such massive information and develop a spatial model of earth features will lead to time and cost reduction and allows analysis of spatial problems more effective than the traditional method. Approach: The objective of this study was to test the potential of GIS in modeling forest road allocation in Ayer Hitam Forest Reserve (AHFR), Selangor, Malaysia. This study is also to compare a road profile (new path) generated from GIS approach (new path) with existing forest road and allocates the best road path for compartment 2 and 14. Data from digital topographic map was used to generate slope class, elevation class, direction and distance. New road paths were determined using spatial analyst. Several module or technique that used were cost weight, reclassify, raster calculator and shortest path modeling. Results: Results showed that road path generated from GIS technique was shorter and avoid more unnecessary slope and elevation. Road profiles such as elevation, slope and length were analyzed and discussed. Conclusion: The result clearly revealed that GIS has strength and played a vital role in modeling forest road allocation effectively and reduced time consuming.
\end{abstract}

Key words: Forest road planning, GIS modeling, road profile, comparison

\section{INTRODUCTION}

Forest management policy in Malaysia was formulated to ensure the sustainability of wood and at the same time conserving and minimizing the negative effect to environment. In forestry, the most important activity in contributing to the sustainable forest management practices is forest road building. Forest road is a network essential for forest harvesting and management. It is a connection between compartments and between concession areas with public road for logs transportation to mills. According to (Hasmadi and Taylor, 2008), proper planning in building forest road not only reduces time consuming but as the same time will reduce cost of road construction and maintenance. Forest road are expensive, complex structure upon which transport efficiency and reliable access to forest both depend. The most problematic feature in harvesting operation in tropical forest is the accessibility into the forest (Muhammad Farid and Abdul Rahman, 1995), maintenance forest road and transportation in harvesting operation (Walker and Lougheed, 1989; Dennis and Rudolf, 1997). Forest road also causes excessive damages to environment, especially soil erosion during timber harvesting operation.

In 1986 the forest engineering plan was introduces to all hill licenses where the logging operator is required to prepare harvesting plans which will show detailed operational plan prior to any logging activities within the area. One of the components in the Forest Engineering Plan is the production of a road plan, which shows the proposed road network within the forest concession area. The road plan incorporates design of the formation level and cross sectional information for the respective logging roads as shown in the profile drawings. In conformance with the ITTO guidelines for the harvesting of hill forest, a preplanned skid trails extraction route should also be incorporated in the road plan.

The traditional practice of preparing road plan and drawing requires various stages of map preparation, drafting, design and planning which are very labor extensive, time consuming and costly (Kamaruzaman and Shamsul, 1999) The growing complexity of planning and design of forest roads has rendered the

Corresponding Author: I. Mohd Hasmadi, Forest Surveying and Engineering Laboratory, Department of Forest Production, Faculty of Forestry, University Putra Malaysia, 43400 UPM, Serdang, Selangor, Malaysia 
traditional method of road planning in future. Therefore there is a need for another approach which is more effective and efficient that is able to fulfill the need for mapping, planning and design of forest road. The application of Geographic Information System (GIS) technologies introduces has been designed to utilize the capabilities of the computer programmers for forest road planning and design. The capability of GIS in integration of spatial and non-spatial information has made it convenient tools in forest road planning.

In Peninsular Malaysia, forest harvesting should be carried out by contractors using guidelines developed by the forestry department peninsular Malaysia headquarters which they had to follow. However in reality, local logging contractor "entered" an area and constructed "preliminary road", thus creating environmental problems. Later the decision was made concerning the harvest system. In many cases using ground-based system, the crawler tractors moved around in search of logs, leaving haphazard distance behind.

In forest road planning, the aspect of cost, time, productivity, distance and reduce erosion are very critical. According to (Sessions, 1992), the network analysis is useful in identifying the minimum cost, time or distances in moving from one point to another in network. In difficult terrain the traditional planning methods are extremely time-consuming and costly, consequently can be hardly applied in future but it can be solved using computerized information system. (Khali and Muhammad Farid, 1991) suggested that construction of the main forest road can be mapped and planned using GIS. This make GIS application in forestry management can be widely used includes in forest road planning, management, recording, strategic planning, operational management planning and system implementation. The objective of this study is to test the potential of GIS in modeling forest road allocation in Ayer Hitam Forest Reserve (AHFR), Selangor, Malaysia. Subsequently, this study compares road profile generated from GIS approach (new path) with existing forest road and allocates the best road path for compartment 2 and 14.

\section{MATERIALS AND METHODS}

Study area: The Ayer Hitam Forest Reserve (AHFR) covers an area about 1,217.90 hectares and is located in Puchong, Selangor Darul Ehsan, Peninsular Malaysia (Fig. 1). The distance of AHFR from University Putra Malaysia (UPM) campus is about 20 and $45 \mathrm{k} \mathrm{m}^{-1}$ from Kuala Lumpur city. The forest is categorized as the lowland dipterocarp forest. The area is characterized by a matured forest stand and the landscape comprised of a gentle undulating topography.

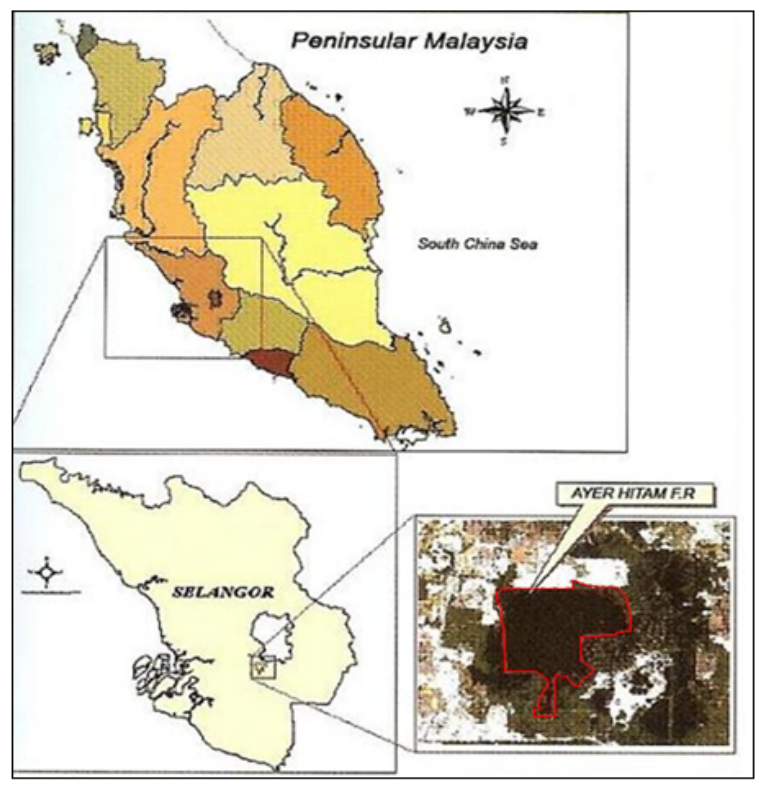

Fig. 1:Peninsular Malaysia showing the location map of the study area

AHFR area was originally about 3500 ha. However in 1997, the forest on the eastern side of Puchong was excised for housing and highways projects (Paiman and Amat, 2006). The Selangor State Government leased this forest in 1996 for 80 years and it is develop for purpose of research and learning especially for Forestry Faculty of University Putra Malaysia. Currently, AHFR has six compartments namely compartments $1,2,12$, 13,14 and 15 . The average temperature is $26.6^{\circ} \mathrm{C}$ and the relative moisture is $83 \%$. Permatang Kumbang is the highest point in this forest with $233 \mathrm{~m}$ above sea level.

Data preparation and classification: The data were prepared by digitizing a 1:20000 scale topographical map of AHFR. Basically four layers of data were digitized with attributes by using PC ARCGIS version 9.0. The four layers were contour, existing road, river and compartments. From these basic layers several new layers were generated which were used in the allocation modeling for forest road planning namely, slope, elevation, distance and direction. Eventually, forest road path were generated from derived classification of the three layers. Table 1 showed classification of each grid layer used for AHFR case study.

Each class was created as thematic layers and then determine by cost weighted of maps. Finally all the three layers i.e., slope, elevation and distance to 
existing road were 1-3 with the highest ranking. A cost weighted approach is determined by giving 50\% weightage to slope and $25 \%$ each to elevation and distance to existing road. Using raster calculator the required cost layer was generated from the following equation:

$$
\begin{gathered}
{[0.5 \times(\text { slope })+0.25 \times(\text { elevation })+0.25 \times(\text { Distance to }} \\
\text { existing road }) \text { as grid }]
\end{gathered}
$$

Raster analysis was based on the cell size of $10 \mathrm{~m}$. Reducing cell size relatively gave more accurate results but with available $20 \mathrm{~m}$ interval contour data, this would not eventually improve the result. In this study direction from or to targets and sources were not considered since it does not impose a major constraint. Once the cost maps were identified, the process of allocation model was applied.

Table 1: Classification of grid layer for road path allocation

\begin{tabular}{llll}
\hline Factor & Class range & Class factor & Verbal class \\
\hline Slope (degree) & $0-20$ & 1 & Gentle \\
& $20-30$ & 2 & Moderate \\
& $>30$ & 3 & Steep \\
Elevation (m) & $0-100$ & 1 & Low \\
& $100-150$ & 2 & Moderate \\
& $>150$ & 3 & High \\
Distance from & $0-500$ & 1 & Short \\
existing road (m) & $500-1500$ & 2 & Moderate \\
& $>1500$ & 3 & Far \\
\hline
\end{tabular}

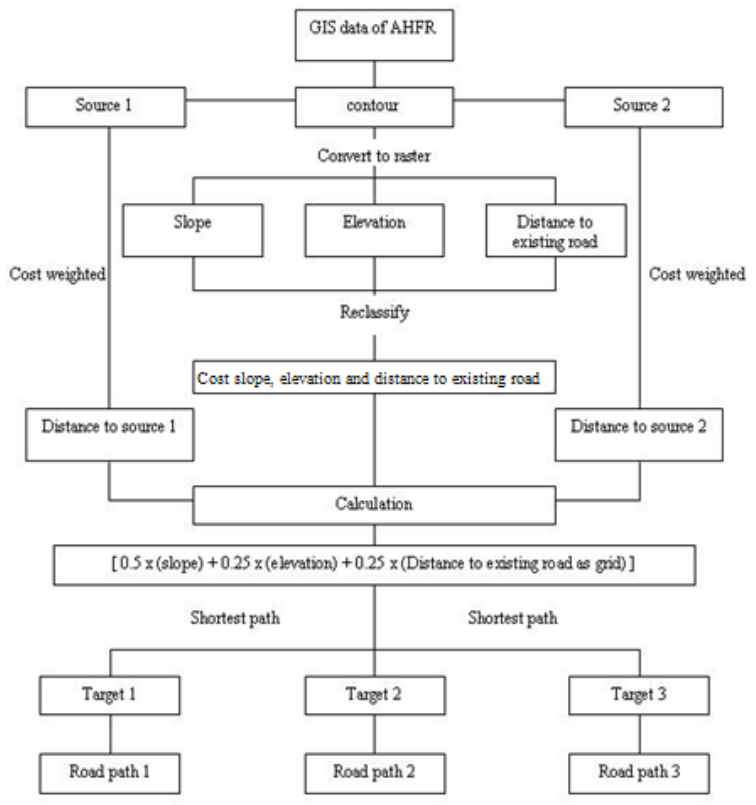

Fig. 2: A simplified flow chart of the model
GIS-allocation model: All parameter layers were transformed to the cost maps and they are ready for GIS evaluation. The next step is find road path between target and source. In this study a total of two sources and three targets were created. The raster of distance and direction gives the least forest path from destination to the target and back to the destination. In this model the selection of target and source may affect the output of the road alignment. From the cost weighted function, the direction was created to give a raster direction of the least cost path from each cell to each source. Once the cost distance and direction of raster were created, the paths to the destination were created automatically. Shortest path model in GIS module was used to accomplish the process of allocating best path alignment for the study area. The model creates a new file of the area by assigning new raster values to all cells. The value is identical to the value of nearest between source and target. The summary of the processes is shown in Fig. 2.

\section{RESULTS}

Existing road and new road (path 1): The results road path alignment model presented in this study is a tool to determine an optimal location based on the classification factor selected. Figure 3 presented the Road path 1 resulting from the calculation from source 1 to target 1 . The automated alignment produced slightly better result as presented in Table 2 .

\begin{tabular}{llll}
\multicolumn{4}{l}{ Table 2: Profile for existing road and new road (path 1) } \\
& $\begin{array}{l}\text { Max. elevation } \\
\text { (degree) }\end{array}$ & $\begin{array}{c}\text { Max. slope } \\
\text { (m) }\end{array}$ & Distance \\
\hline Existing road & 90 & 27 & 4150 \\
New road (path 1) & 90 & 23 & 4070 \\
\hline
\end{tabular}

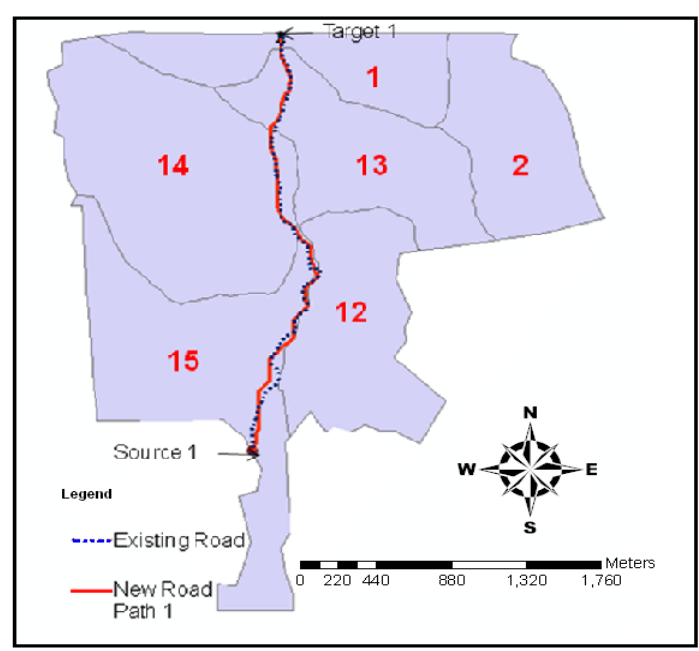

Fig. 3: New road (path 1) overlay with existing forest road 


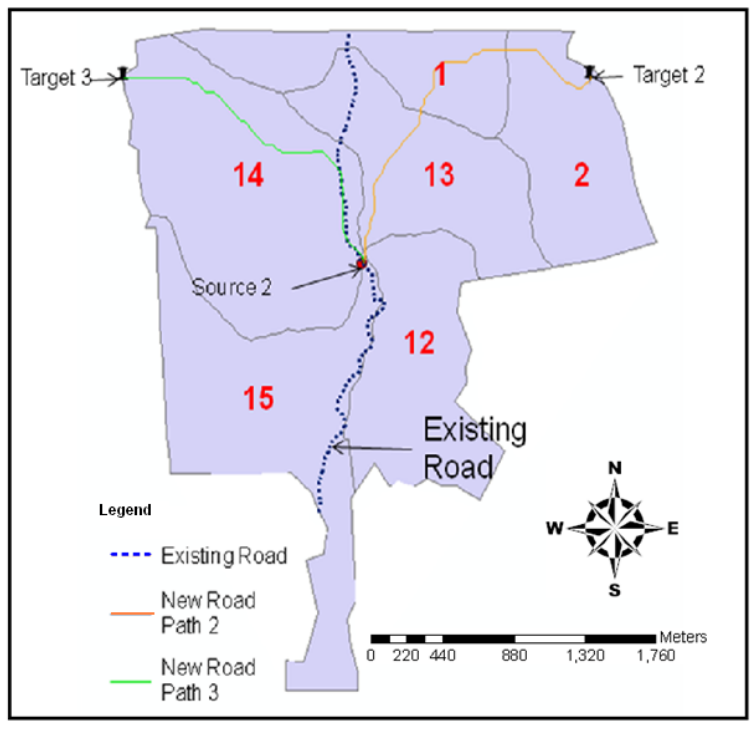

Fig. 4: Road path 2 and road path 3

Table 3: Road path 2 and 3 profile using GIS-best path modeling

\begin{tabular}{llll}
\hline & $\begin{array}{l}\text { Max. elevation } \\
(\mathrm{m})\end{array}$ & $\begin{array}{l}\text { Max. slope } \\
\text { (degree) }\end{array}$ & Distance (m) \\
\hline Road path 2 & 118 & 29 & 3282 \\
Road path 3 & 150 & 29 & 2912 \\
\hline
\end{tabular}

Road path 2 and 3: The result of the alignment of new road (path 2 and 3) were presented in Fig. 4. Meanwhile Table 3 showed summary of road profile for road path 2 and 3 using GIS modeling.

\section{DISCUSSION}

Existing road and new road (path 1): The red line in Fig. 3 was generated automatically from the path model, meanwhile the dotted blue line was the existing forest road through drawing method. The result depicted approximately $27 \%$ road overlay were shown the differences, especially for slope and road distance. A small differences was due to variation of topography is not too steep along the path. However, the key idea is that automatic alignment derived from this model produced qualitative spatial reasoning. The distance created using path modeling was 4078 and $4150 \mathrm{~m}$ by drawing approaches. This showed that new road have shorter length by $72 \mathrm{~m}$ difference. Meanwhile maximum slope involve in the alignment was 27 degree (existing road) and 23 degree for new road (Path 1), where the difference was 4 degree. The maximum elevation was equal for both approaches with $90 \mathrm{~m}$, respectively.

Road path 2 and 3: Results revealed that the emphasis of the path was to avoid the most cost anomalies in the planning. The higher slope and road length incurred high construction cost were totally avoided. In fact, the road allocation from source 2 to target 3 and 4 will reduce environmental impact to the forest ecosystem. The maximum elevation and slope for building the paths were $150 \mathrm{~m}$ and 29 degree. The Majority route alignments were located at the moderate class. The distance of route (path 2 and 3) is approximately 6194 $\mathrm{m}$. The research presents the procedures for determination of forest road path that result from AHFR. The spatial data on forest road can be applied in various levels of forest management planning. This model generates cumulative sum by successive road path in the direction for evaluation the road profiles. On the other hand, the model enables relatively fast and consistent evaluation if apply to large forest area with the help of spatial data analysis.

\section{CONCLUSION}

Several conclusions can be derived from this study; firstly GIS technique was proven useful to be used in forest road planning because it can be used as a base map for considering optimum alignment of forest road network. Secondly, it is useful for initial planning processes. Forest road that created using GIS technique had less environmental impact on forest degradation because high risk area or sensitive area were avoided because the road being build only can passed low class area and moderate which slope do not exceed 30 degree and elevation below than $150 \mathrm{~m}$. GIS technique should be used nowadays because it fast, easy and show satisfying result for road allocation through the implementation of the procedure defined above in the context of Ayer Hitam Forest Reserve. In fact, forest road map can be used in assessing forest openness, costs of road maintenance, required road construction quality and other factors related to forest operations such as silviculture operation. However this preliminary study established GIS as the prime analytical tools to be used, should be further details research need to be carried out. In order to improve the study a comprehensive data and model development should be brought in the experiment.

\section{REFERENCES}

Dennis, P.D. and H. Rudolf, 1997. Forest harvesting and transport: Old problems, new solutions. Proceeding of the 6th World Forestry Congress, Antalya, Turkey, Oct. 13-22, Antalya, Turkey, pp: 171-186. 
Kamaruzaman, J. and S. Shamsul, 1999. Geographical information system for forest road planning: A case study of Balah Forest Reserve, Ulu Kelantan. Proceeding of the Tropical Forest Harvesting: New Technology Examined, Nov. 22-24, Published by FRIM, Terengganu, Malaysia, pp: 76-90.

Khali, A.H. and A.R. Muhammad Farid, 1991. The application of Geographic Information System (GIS) in determining suitable logging area: A case of Ulu Selangor Forest. Proceeding of the ASEAN Seminar on Land Use Decision and Policies: Will Tropical Forest Survive Their Impacts? Oct. 18-20, Published by FRIM, pp: 56-61.

Hasmadi, M. and J.C. Taylor, 2008. Sensitivity analysis of an optimal access road location in hilly forest area: A GIS approach. Am. J. Applied Sci., 5: 1686-1692.

Muhammad Farid, A.R. and D. Abdul Rahman, 1995. Design of forest road for hill forest management: A case study at Ulu Muda Forest Reserve, Baling Kedah. Proceeding of the Seminar Kajian Pembalakan Terhadap Waduk di Hutan Simpan Ulu Muda, Jan, 23, University Technology Malaysia, Published by UTM, Johore, Malaysia, pp: 22-29.
Paiman, B. and R.Y. Amat, 2006. Hutan Simpan Ayer Hitam, Warisan Komuniti Koridor Raya Multimedia (in Malay). 1st Edn., University Putra Malaysia Press, ISBN: 978-983-3455-91-1, pp: 34.

Sessions, J., 1992. Using network analysis for road and harvest planning. Proceedings of the Workshop on Computer Supported Planning of Roads and Harvesting, Aug, 26-28, Published by Oregon State University, Feldafing, Germanym pp: 26-35.

Walker, H.D. and W.H. Lougheed, 1989. Road network design in wood supply analysis. Forest Chronicle, 65: 431-440. 